\title{
Does intra-individual variability in narration matter and for what?
}

\author{
Kate C. McLean ${ }^{1}$ \\ Monisha Pasupathi ${ }^{2}$ \\ Andrea F. Greenhoot ${ }^{3}$ \\ Robyn Fivush ${ }^{4}$ \\ ${ }^{1}$ Western Washington University \\ ${ }^{2}$ University of Utah \\ ${ }^{3}$ University of Kansas \\ ${ }^{4}$ Emory University
}

McLean, K. C., Pasupathi, M., Fivush, R., Greenhoot, A. F., \& Wainryb, C. (2016). Does within person variability in narration matter and for what? Journal of Research in Personality, 69, 55 - 66.

Key words: intra-individual variability, narrative identity, personality, well-being

Author Note. We thank our undergraduate research assistants at Western Washington University, University of Kansas, and University of Utah for data collection and coding, particularly Elizabeth Sigurdson and Kris Oldroyd for their help with the planning and management of data collection on recognizability, and our participants for their time. We also thank Western Washington University for helping to fund this project. Correspondence can be addressed to the first author at: Western Washington University,

516 High Street, MS 9172, Bellingham, WA 98225 


\begin{abstract}
Building on calls to examine intra-individual variability in personality, we examined such variability in narrative. In Study 1 , participants $(n=553)$ provided three narratives (either self-defining, turning point, transgression, low point, or trauma memories; $n=$ 1659 narratives). Narratives were coded for coherence, autobiographical reasoning, resolution, and emotional expression. Variability was highest for resolution, lowest for coherence, and was related to well-being, depending on narrative feature and event type. In Study 2, participants $(n=103)$ engaged in a 'narrative recognition' task to see if they could identify which narratives came from the same individual. Recognizability was substantial, but not related to variability or well-being. Results showcase the importance of addressing intra-individual variability by narrative feature and event type.
\end{abstract}




\section{Does intra-individual variability in narration matter and for what?}

Historically, personality researchers have primarily focused on the stability of individual differences across time and context (e.g., Costa \& McCrae, 1994): that is, how individuals differ from each other in stable ways. Thus, despite the fact that personality traits are variable across contexts (e.g., Mischel \& Peake, 1982; 1983; Mischel \& Shoda, 1995; see also Noftle \& Fleeson, 2015 for a review), the conceptual underpinning of much of personality theory is that a stable 'core' underlies contextual fluctuation (e.g., Block, 1981; Costa \& McCrae, 1980). Methodologically, aggregation across contexts is viewed as a way to smooth out variation due to error in measurement, normative developmental shifts, or seemingly irrelevant contextual shifts (Funder, 1983), and this approach has revealed impressively high stability in people's relative rankings on personality traits, sometimes over quite long spans (e.g., Roberts \& DelVecchio, 2000). Further, high variability across various aspects of personality has generally been associated with poorer psychological adjustment (e.g., Cote, Moskowitz, \& Zuroff, 2012; Donahue, Robins, Roberts, \& John, 1993; Dunlop, Walker, \& Weins, 2013), although the level of personality appears to matter with greater variability in goals, for example, associated with more positive outcomes (Dunlop et al., 2013).

Despite the relative emphasis on the stability of personality, there are alternative orientations. The first comes from the dispositional signature literature, in which variation in traits across contexts is viewed as a potential source of stability in personality (e.g., Fournier, Moskovitz, \& Zuroff, 2009; Mischel \& Shoda, 1995). That is, one may reliably shift behavior depending on contextual 
demands, which turns attention from variation between people to variation within people. Here we see that relative rank is often preserved, but that if-then dispositional signatures are also meaningful parts of personality; there can be stability in variability.

Fleeson and Jayawickreme (2015) have recently called for greater attention to within-person variability in traits in the context of the Five Factor model, employing methods such as experience sampling. They have shown that there is indeed great within-person individual variability in the manifestation of traits in daily life, often more than the variability between persons, yet the range or form that this variability takes within persons is relatively stable (e.g., Fleeson, 2001; Noftle \& Fleeson, 2010). Fleeson and Jayawickreme (2015) make the claim that this within-person trait variability is due to the dynamics of social-cognitive processes related to how individuals engage with various contexts (e.g., goals, mood, roles, encoding processes), and such variability may be as important in characterizing individuals as are trait descriptions.

Considering the narrative level of personality, McAdams (1995) argued that this part of personality is highly contextualized and offers a more idiographic perspective on the person than other levels of personality (McAdams, 1995; McAdams \& Manczak, 2011); this raises the possibility that it may be more variable than other levels. However, like much of the research on traits, research in this area has predominantly focused on aggregation of features across narratives, overlooking the potentially rich sources of information about personality that come from examining within person variability in narrative (cf., Dunlop et al., 2013; Dunlop, 2015; Pasupathi, McLean, Fivush, Greenhoot, \& Wainryb, in preparation). Thus, we consider where we might see such variability in narrative, examine whether the extent to which individuals' stories vary across the narration of similar events may be an important 
indicator of individual well-being, and examine whether this variability is indicative of a 'narrative style,' or signature that is visible to others.

\section{Intra-individual Variability in Narrative: Where, and Does it Matter?}

One of the implicit and deeply held assumptions embedded in narrative research is that individuals are consistent in how they narrate events. This assumption is evident in the ways that researchers often aggregate across narratives (e.g., Blagov \& Singer, 2004; Mansfield, Pasupathi, \& McLean, in press; McAdams, Anyidoho, Brown, Huang, Kaplan, \& Machado, 2004; McLean, Wood, \& Breen, 2013), elicit only a single event as a "window" into narrative identity (e.g., McLean \& Pratt, 2006), or hypothesize stability in narrative over time (McAdams, Bauer, Sakaeda, Anyidoho, Machado, Magrino-Failla, White \& Pals, 2006; Thorne, Cutting, \& Skaw, 1998). This assumption, and associated methodological strategies, stem from the roots of many narrative researchers in personality psychology, and the emphasis on a stable core as central to the definition of personality (see Fleeson \& Jayawickreme, 2015).

Aside from the stability assumptions embedded in dominant personality approaches, the narrative identity literature itself also provides deep theoretical reasons to argue for stability in narrative. Narrative represents the level of personality most closely linked to, or in fact representative of, identity (McAdams, 1988; McAdams \& McLean, 2013; Singer, 2004). As such, McAdams has argued that narrative serves an integrative function, and can be used to create unity for an individual's personality - to fit the pieces together, so to speak (e.g., McAdams \& Cox, 2010; McAdams \& Olson, 2010). From this perspective, we would expect to see that high variability across narratives might represent a lack of unity or integration, and thus be associated with poor outcomes. Indeed, Dunlop et al. 
(2013) found that those with more variability in narratives across different domains (e.g., professional and personal) had less positive adjustment (see related findings on traits in Donohue et al., 1993). Further, Dunlop et al. (2013) also found that greater thematic consistency across narratives was related to more positive adjustment (see also McLean, 2008 for a discussion of the developmental implications of thematic consistency).

In contrast to these arguments focused on the importance of narrative integration (conceptualized as low variability) for psychological health, from a contextualist perspective, higher variability in narrative might contribute to flexibility and adaptability (Pasupathi et al., in preparation). Indeed, McAdams (e.g., 1995; McAdams \& Manczak, 2011) emphasizes the evolving nature of narrative, and we already know that there is variability in the narration of events for different audiences (McLean, 2005; McLean \& Jennings, 2012; Weeks \& Pasupathi, 2010), over time (Josselson, 2009; McAdams et al., 2006; Thorne et al., 1998), and for different types of events (e.g., Banks \& Salmon, 2013; Fivush, Sales \& Bohanek, 2008; Waters, Bauer \& Fivush, 2013), suggesting that stories are not set in plaster. In the present paper, we focus on one specific type of narrative variability: variability in how individuals narrate similar types of events at one point in time, in relation to both well-being and to being recognizable to others.

\section{Does Variability differ for Type of Event and does it Matter for Psychological Adjustment?}

Fleeson and Jayawickreme (2015) argue that every context evokes expectancies, goals, and self-regulation strategies that should shift how trait-related behaviors manifest, which is based on the idea that not all events are equal. We agree with this premise, and we addressed this issue of contextual variation in the context of narrative in two ways, within and between persons. 
There is some emerging evidence that high intra-individual variability in narratives about different life contexts is linked to poor adjustment, and is perhaps indicative of a lack of identity integration (Dunlop et al., 2013). We note that our examination is somewhat distinct from this extant work. For example, Dunlop et al. (2013) examined variability across narratives about different contexts, operationalized as roles across various domains (e.g., professional, personal) and variability was examined in the themes that occurred within a person's narratives. However, in Dunlop et al.'s (2013) design event type and person were confounded as people provided an event from a professional and from a relational context. Thus, variability in the narratives could be due either to a person narrating different events differently, or to a person being simply more variable in narration regardless of type of event. In fact, recent empirical and theoretical work has argued that different types of events, or contexts, require different types of narrative processing (see Mansfield, 2015; Waters et al., 2013). Thus, in our study, we asked how people did (or did not) vary in the way they narrated several events from the same class of experiences. For example, do people tell their self-defining memories with the same narrative features, or do they tell them in different ways, and does this matter? We also included five different types of events, permitting us to examine whether variability depends on the type of event, and whether within-person variation has different implications for wellbeing depending on the type of event.

We chose five common narrative prompts: turning point, self-defining, transgression, low point, and trauma memories as our between-person comparison because they have different implications for identity and well-being. By definition self-defining memories are identity related (Singer \& Moffitt, 1991-1992). Turning points are also often viewed as an identity-defining (e.g., Mclean \& Pratt, 
2006), signaling a meaningful change within a person's conception of his or her identity. The other three memories - low points, traumas, and transgressions - are not so evidently linked to identity. Indeed, these are the kinds of events that are more likely to be a challenge to identity, potentially even events that individuals want to distance from the self, particularly transgressions (e.g., Baumeister, Stillman, \& Wotman, 1990; cf., Lilgendahl, McLean, \& Mansfield, 2013; Mansfield et al., 2015; Mansfield, McLean, \& Lilgendahl, 2010). Furthermore, whereas these three types of events are by definition about negative experiences, self-defining and turning point events can be positive or negative. Finally, self-defining and turning point memories vary not only by the emotionality of the event, but also by the way the event may become self-defining (e.g., learning what one is as well as learning who one no longer is; Pasupathi, Mansour, \& Brubaker, 2007; Pasupathi, McLean, \& Weeks, 2009; Pasupathi, Billitteri, Mansfield, Wainryb, Hanley, \& Taheri, 2015).

Thus, we expected that, overall, self-defining and turning point memories would show more variability than the more negative memories, and that narrating identity-linked memories in more variable ways may be more adaptable. In contrast, transgression, low point, and traumatic experiences always pose a problem for the self that must be resolved in some way, and there are cultural master narratives for these types of events that provide narrative templates for story construction (McLean \& Syed, under review). Thus, individuals may show less variability when narrating these kinds of experiences compared to self-defining and turning point memories, and this lower variability may be related to higher well-being. However, in considering these ideas, it is also important to 
ask about variability in what aspect of narrative, because differences in variability between different types of events might hinge on the specific feature of narrative that is being examined (Pasupathi \& Oldroyd, in press).

\section{Is Variability Feature-Specific, and does the Feature Matter for Psychological Adjustment?}

Narrative researchers have identified an array of narrative characteristics that are important to psychological adjustment, and these characteristics can reflect a range of underlying factors, from the development of cognitive skills to sensitivity to context.

Therefore, we expected that the relation between variability and well-being would differ depending on what feature of narrative we were examining. Building from recent theoretical arguments about the central features of narratives for understanding well-being (Adler, Lodi-Smith, Philippe, \& Houle, 2015), we examined whether or not there was evidence for variability in four basic features of narrative - coherence, autobiographical reasoning, emotional expression, and resolution - and whether variability in these dimensions was associated with psychological adjustment.

Narrative coherence is often conceptualized as a defining feature of a 'good story' (e.g., Reese, Haden, Baker-Ward, Bauer, Fivush, \& Ornstein, 2011). Coherence is part of the structure of a story, and can be broadly defined as the degree to which a story 'holds together': does it make sense? Reese et al. (2011) called coherence a necessary but not sufficient aspect of a high quality narrative. In other words, if the story is not coherent, other characteristics may not matter because the story needs to make sense first and foremost. In the current study, we examined three aspects of coherence: contextual, chronological, and thematic. 
Contextual coherence addresses the background details necessary for understanding a story, such as when and where it happened. Chronological coherence addresses the order of events - what happened and when. Thematic coherence provides the affective and evaluative information necessary for understanding the point of a story. Reese et al. (2011) argued that each of these aspects of coherence is a developmental skill, as contextual and chronological coherence emerge in middle childhood and early adolescence, and are related to emerging linguistic and cognitive skills, and thematic coherence in later adolescence, with the emergence of the life story (Habermas \& de Silveira, 2008). Thus, we would expect that emerging adults would have the necessary skills to tell coherent stories. Because coherence is a necessity for an adequate narrative, we expected that coherence would be relatively less variable than other narrative characteristics. Further, because incoherence suggests a lack of clarity about what happened, it is difficult to imagine an event for which incoherence would have positive implications. Thus, for coherence, we expected that high coherence and low variability would be associated with positive adjustment, and this would be true across narrative types.

Autobiographical Reasoning is a dimension of narrative focused on the subjective impact of the event on the self. The construction and telling of personally important stories is viewed as an act of identity work (e.g., McLean, Pasupathi, \& Pals, 2007): in constructing personal stories we are constructing the self. To construct stories that help us to understand who we are, and explain ourselves to others, scholars have argued that we should imbue narratives with explicit explanations of what these events mean to us 
(Habermas \& Bluck, 2000; Lilgendahl \& McAdams, 2011; McLean \& Thorne, 2003; Pasupathi et al., 2007). That is, one must go beyond the details of a past event to explain what one learned about the self it.

There are various ways to assess autobiographical reasoning, and we examined two: meaning-making, and positive and negative impact statements. Meaning-making is identified when individuals make explicit statements about how their understanding of themselves has changed from reflecting upon a past event, representing efforts at personal understanding and identity development (e.g., McLean \& Pratt, 2006). This has been primarily defined as drawing explicit lessons (e.g., I won't ever put myself in that situation again) and insights (e.g., I realized I'm just not good at taking criticism.) from the past. Impact statements also address what one has gleaned from a past event, but cast a wider net than the specificity required for meaning-making, and differentiate between positive or negative effects of an event on oneself (e.g., "It made me a stronger person," or "I became very distant from my family"). Together, these constructs offer a relatively comprehensive assessment of autobiographical reasoning.

The degree to which autobiographical reasoning is healthy depends on whether that reasoning is positive or negative (Banks \& Salmon, 2013; Greenhoot, Sun, Bunnell, Lindboe, 2013; Fivush, Merrill, \& Waters, in press; Lilgendahl, 2014; Lilgendahl \& McAdams, 2011; Waters, Shallcross \& Fivush, 2013), as well as on the type of event about which one is reasoning (Greenhoot \& McLean, in preparation; Lilgendahl et al., 2013; Pasupathi \& Wainryb, 2010). In terms of types of reasoning, not surprisingly, making negative meaning is associated with poor well-being (Banks \& Salmon, 2013; Greenhoot et al., 2013; Lilgendahl et al., 2013; Waters et al., 2013). In terms of type of event, scholars have recently argued that different events require different types of narrative 
processing (Mansfield, 2015). For example, making meaning in narratives of self-defining or turning point memories is associated with healthier development, such as identity achievement and ego development (McLean \& Pratt, 2006; McLean et al., 2014). Thus, since self-defining and turning point memories are already defined as personally important, we would expect to see high variability in reasoning as less healthy. Conversely, Pasupathi and Wainryb (2010) argue that over-imbuing negative events, such as transgressions, with self-relevant meaning could be maladaptive, but perhaps only if the meaning is negative. Indeed, some may articulate a sense of personal growth in narrating negative events, and doing so has been linked to adaptive outcomes (Lilgendahl et al., 2013; Mansfield et al., 2010; Mansfield, et al., 2015). Therefore, we would expect more variability in autobiographical reasoning in narratives about negative events because some may benefit from being imbued with meaning, whereas for others it might be healthier to distance oneself from the event, and we expected that this flexibility would be associated with higher well-being (Pasupathi \& Wainryb, 2010).

In terms of how much individuals vary their emotional expression, we expected that event types would differ in amount of within-person variability. Transgressions, low points, and traumas are, by definition, highly emotional in relatively negative ways, whereas self-defining and turning point events, by definition, can be positive or negative. Thus, we predicted the more negative memory narratives to be less variable in emotional expression than the identity-linked narratives. Although there are expectations about relationships between average emotional expression in narratives and well-being (see Pennebaker \& Chung, 2011 for a review), it is less clear whether variability in emotional expressivity would be linked to well-being, and in our analyses (as described below; see also Fleeson \& Jayawickreme, 2015), we controlled for the mean-levels of the narrative features. Average emotional expression is 
likely to be related both to emotional expression by event type and potentially to well-being, a point we return to in the discussion.

We, therefore, merely asked whether any significant relationships with variability emerged, after controlling for mean-level emotional expressivity.

The final characteristic of the narratives that we examined was the degree to which the events were resolved. Resolution has emerged as a critical aspect of storytelling in relation to well-being (see Lilgendahl, 2014 for a review; King, Scollon, Ramsey, \& Williams, 2000; Pals, 2006; cf., Greenhoot et al., 2013). However, given that not all events require resolution (e.g., positive events), we expected to see more variability in this feature of narrative relative to others. Similar to our reasoning about mean levels of emotional expression, we did not have hypotheses about the relation between variability in resolution and well-being.

Thus far, in keeping with the broader literature on narrative and adaptation (e.g., Adler et al., 2015), we have addressed variability in direct relation to individual well-being. However, a unique feature of this level of personality is that narrative is social in nature. Stories are not created and maintained in a social vacuum - they are intricately linked to our interpersonal, social lives (e.g., Bruner, 1990; Fivush \& Zaman, 2015; McLean et al., 2007; Pasupathi, 2001; Thorne, 2000). Therefore, if narrative does indeed serve an integrative function, this level of personality should provide coherence to the self that is also detectable by others. In other words, if we experience a sense of narrative integration, that should be observable to others.

Communicating ourselves via our stories is part of what keeps us tied, and even responsible, to others (Pasupathi, 2001; McLean \& Pasupathi, 2011). Indeed, there is substantial evidence concerning the importance of sharing stories with others as a part of 
defining the self and developing and maintaining relationships with others (Alea \& Bluck, 2003; Fivush, Bohanek \& Duke, 2008; McLean, 2005; Pasupathi, 2001; Thorne, 2000). In other literatures, there is support for the notion that being perceived accurately is related to higher well-being (Human, Lauren Biesanz, Finseth, Pierce, Le, 2014). In other words, our stories matter to us, and they matter to others.

Taking this argument further raises the question of whether variability in narratives might reduce the extent to which others can accurately perceive our personalities in narrative form. To examine this, in Study 2 we approached the issue in ways similar to thin-slice assessments of traits (e.g., Borkenau, Mauer, Riemann, Spinath, \& Angleitner, 2004; Tackett, Herzhoff, Kushner, \& Rule, 2015). Adopting the perspective that having one's narratives be recognizable to others may be socially adaptive, we asked first whether an individual's narratives could be recognized by others, then whether the degree of recognizability was related to variability in the features of narratives we examined, and finally whether that recongizability was related to well-being.

\section{Current Study}

The current study was driven by three questions about within-person variability in narrative: 1) In what features of narrative is within-person variability most evident?; 2) Is variability associated with psychological health?; and 3) Is variability associated with being recognizable to others? We were also interested in whether the answers to these three questions depended on the type of event being narrated. We addressed the first question by examining the narrative features described above across three narratives per person, for five distinct types of events: self-defining, low points, turning points, traumas, and transgressions. Thus, analysis of variability was 
within-person, and analysis of differences by type of event was between-person. We then examined whether variability in these narrative features was associated with psychological adjustment, and we did this separately for the five types of events. We included two distinct measures of psychological adjustment: life satisfaction and depression. In our analyses we took into account that the implications of variability may differ depending on average levels of a given construct, so we controlled participants' average scores on narrative features (e.g., Fleeson \& Jayawickreme, 2015).

\section{Method: Study 1}

\section{Participants}

Participants were 553 from two large state universities, one Midwestern, and one in the Western U. S., who participated in a study of narrative and well-being (Greenhoot \& McLean, in preparation); 67\% were female, and 79\% were European American. Participants were randomly assigned to write about one of five different types of events: self-defining $(n=119)$, low point $(n=105)$, turning point $(\mathrm{n}=107)$, trauma $(\mathrm{n}=111)$, and transgression $(\mathrm{n}=111)$.

\section{Procedure}

Following informed consent, participants wrote their narratives on paper, and completed survey items on a computer program used for the remainder of the session (written with Media Lab v2008; Empirisoft, 2008). Once finished, participants were debriefed, given information about available counseling resources, and thanked. Participants were given course credit for participation, which took an average of $1.5-2$ hours. 


\section{Measures}

Narrative Prompts. Participants were randomly assigned to write three personal narratives in response to one of five types of prompts: self-defining, turning point, transgression, low point, and trauma. Self-defining memories are highly emotional, represent an enduring theme in one's life, and help to explain who one is (Singer \& Moffitt, 1991-1992). Turning points are episodes in which one underwent an important change in self-understanding (McAdams, 2006). Transgressions were defined as the worst thing one had ever done, which may have resulted in physical or psychological harm to another, and guilt or shame (Mansfield et al., 2010). Low points were described as extremely negative events, which could include emotions such as despair, disillusionment, terror, guilt, or shame (McAdams, 2006). Traumas were defined as the most negative, stressful, or traumatic events of one's life (Greenhoot et al., 2013). For each prompt participants were asked to provide details about where they were, whom they were with, what happened, and their reaction and others' (if relevant). Narratives were 196 words on average ( range $=24$ to $522 ; s d=92.2$ ).

After writing narratives, participants also completed several assessments that we do not examine here: ratings of memory characteristics, survey items about memory telling, a memory about abuse and of overcoming a struggle, surveys assessing health, abuse history, Post-Traumatic Stress Disorder, and state emotion.

Surveys. We used two standard surveys to assess well-being. The Center for Epidemiologic Studies Depression Scale (Radloff, 1977) includes 20 items on the frequency of various symptoms of depression (e.g., "I was bothered by things that don't usually bother 
me.”) with ratings of $1-4$ (rarely - most of the time) $(\alpha=.90)$. The life satisfaction scale (Diener, Emmons, Larsen, \& Griffin, 1985) contained 5 items (e.g., "in most ways, my life is close to ideal") rated from 1- 7 (strongly disagree - strongly agree) $(\alpha=.87)$. Narrative Coding

Coherence. The coherence of the narratives was evaluated with a coding scheme developed by Baker-Ward, Bauer, Fivush, Haden, Ornstein, \& Reese (2007). This scheme allows identification of three dimensions of coherence on a scale of 0 (complete absence of the dimension) to 3 (fully coherent use of the dimension). The dimensions are: context which places the event in time and location; chronology, the degree to which the narrative is temporally organized; and theme, which assesses the clarity of topic in the narrative. Coherence was scored by two research assistants and a trained master coder. Reliability between each research assistant and the master coder was acceptable on $10 \%$ of cases, with percent agreement acceptable for context (86\%), chronology (84\%), and theme $(84 \%)$.

Autobiographical Reasoning. Each of the memory narratives was coded for sophistication of meaning on a four-point scale (McLean and Pratt, 2006). A zero indicated no explanation of the meaning of the event. Narratives were scored as one if there was a specific lesson that the reporter learned from the event. A score of two was assigned to narratives that contained vague meaning; narratives of this sort describe some growth or change in the self, but the specifics of the change are not clear. Narratives were scored as three if there was evidence that the reporter gleaned specific insight from the event that applies to broader areas of the reporter's life. Three research assistants who had acceptable reliability with a trained graduate student coded meaning (intraclass $r$ range $=.83$ - 
.89). The other measure of autobiographical reasoning was impact statements. We coded for impact by identifying the frequency of references to the psychological or relational impact of the event on the narrator, for better (positive impact) or for worse (negative impact) (Greenhoot et al., 2013). Impact statements do not include references to things that propelled the action in the event itself, but rather consequences of the event that lasted longer than the event itself. Impacts that were not clearly valenced were quite rare and were included in the positive/neutral category. Two research assistants obtained acceptable reliability for positive (intraclass $r=.85)$ and negative impact (intraclass $r=.71$ ) on $10 \%$ of cases, and then completed the impact coding.

Emotional Expression. We captured emotional expression by using the Linguistic Inquiry and Word Count program (LIWC; Pennebaker, Booth, \& Francis, 2007) to score the density of positive and negative emotion terms in each narrative. We edited the LIWC dictionary so that it scored implicit and explicit emotion terms, and did not count emotion-laden words (e.g., abuse). Positive and negative emotion terms were calculated as a proportion of the overall word count for each narrative.

Resolution. Resolution coding measured the degree to which the participant explained how the main problem in a narrative was resolved. Resolution was coded on a 0 to 2 scale, with a 0 representing no resolution, 1 indicating a vague reference to a resolution (e.g., "Things are better now") and a 2 indicating specific mention of the way in which the main problem was resolved.

Two research assistants obtained acceptable reliability on $10 \%$ of cases (intraclass $r=.90$ ), and then coded the rest of the narratives.

\section{Results: Study 1}

\section{Power, Descriptives, and Preliminary Analyses}


Power analyses using Gpower 3.1 (Faul, Erdfelder, Lang, \& Buchner, 2007) indicate that we have adequate power (.80) to detect small effect sizes for event-based differences in variability across our 9 narrative features, as well as substantial power to detect small effects in correlational analyses at the level of the whole sample. For examining correlations within event-type, we also had adequate power to detect medium effects with at least 105 participants per event-type,

Our first goal was to examine the variability of different narrative features, across five prompts. Variability for all codes was initially computed as the standard deviation of the code across the three narratives. In addition, we computed two additional variability scores from that basic score. In the first case, we computed variability as a proportion of range measure by dividing the standard deviation by the observed range for the variable; this allows us to compare variability of different narrative features on a common metric. Second, we computed a residualized variability score by regressing those standard deviations on the mean, and the meansquared, for each narrative feature, and saving the standardized residual (see Baird, Le, \& Lucas, 2006). This measure reflects variability over and above what is expected based on the participants' average score on a feature, and provided a basis for looking at correlations of variability scores with adjustment. Because standardized residuals have a mean of zero, this measure does not provide a good metric for comparing variability across different features.

We first provide descriptive statistics on variability, including correlations of variability between different narrative features. We then examined whether variability differed as a function of target participant gender, event type or narrative feature. Table 1 
provides descriptive data for the average and the within-person variability scores for each narrative feature, as well as for our indicators of well-being.

As can be seen in Table 1, variability was evident in most narrative features, although the degree of variability ranged depending on the feature. A series of one-sample t-tests for the variability scores revealed that in every case, the variability we observed was significantly different from zero, $t$ 's $>13.7, p$ 's $<.001$. Table 1 also shows that the range and average for a given narrative feature constrains the degree of variability that is evident on that feature. For this reason, to compare across different narrative features, we need a common metric; the last column in Table 1 shows the variability scores as a proportion of the possible range of the variable to allow such comparisons. Variability within persons often amounted to, on average, 8 - $20 \%$ of a narrative feature's potential range.

Table 2 shows the correlations of the variability scores across features. If variability is a general property of individuals, then we would expect multiple significant and positive correlations among variability features. In Table 2, correlations in raw scores are presented above the diagonal, while correlations in the residualized variability scores, after controlling for mean-levels (both means and means squared), are presented below the diagonal. Table 2 suggests that within-person variability on one narrative feature is largely independent of within-person variability on other features, and that correlations between intraindividual variability on one feature or another are largely due to mean level associations.

\section{Are some Aspects of Narratives more Variable than Others, and does Event-type Matter?}


To address this issue, we analyzed proportional variability scores in a GLM with event prompt as a between-person variable, and narrative features as a within-person factor. We included mean and squared mean scores for all measures as covariates. The results yielded significant multivariate effects of measure, $F(8,492)=6.4, p<.001, \eta 2=.09$, but no omnibus effects of condition or interactions. Note that including gender did not change these effects, and there were no significant main effects or interactions involving gender.

For the effect of measure, we conducted pairwise comparisons that examined variability for each narrative feature compared with each other feature. As can be seen in Table 1, resolution was significantly more variable than all other narrative features $(p<$ .05). Positive/neutral impact statements were the second-most variable, and were significantly more variable than positive emotion language and chronological coherence, and significantly less variable than resolution $(p$ 's $<.05)$. Contextual and thematic coherence, meaning-making, and negative impact statements did not differ from one another and fell in the mid-range. Chronological coherence and positive emotional expressivity were the least variable, and were significantly less variable than all other narrative features (pairwise comparisons, $p^{\prime} s<.05$ ).

Table 3 presents correlations between residualized variability scores and our indicators of well-being. Correlations are presented for the overall sample in the upper part of Table 3, and then separately for the five event prompts below. Overall, there were no significant relationships between residualized variability and well-being measures. However, specific significant relationships emerged for particular types of events. Notably, higher variability in resolution for low points was associated with higher depression 
scores. For self-defining memories, higher variability in contextual coherence, meaning-making, and positive/neutral impact statements was linked to lower life satisfaction and higher depression; however, higher variability in thematic coherence was associated with higher well-being. For turning points, higher variability in meaning-making was associated positively with life satisfaction, and higher variability in negative impact statements was linked to lower life satisfaction.

\section{Discussion: Study 1}

Overall, these findings suggest that variability is important beyond an individual's average narrative tendencies, or "style," in predicting well-being. However, the import of that variability is particular to the type of event, and the feature of narrative. For example, the link between higher variability in resolution of low points and higher depression scores suggests that for low points, it may be important for well-being both to resolve those experiences, and to do so consistently across different low points. By contrast, the import of building meaning in turning point narratives may be better done in varying ways. That is, low points may demand resolution, but not all turning points demand meaning.

\section{Study 2}

In Study 2 we moved beyond a purely individual focus on intra-individual variability to examine whether that variability was first, recognizable to others, and second, whether such recognizability was related to well-being. Indeed, narrative is by definition social in nature. Stories ranging from the most memorable event of the day (Pasupathi et al., 2009), to highly emotional experiences (Rimé, Mesquita, Philippot, \& Boca, 1991), to self-defining memories (Thorne, McLean, \& Lawrence, 2004) are told at least once to 
others, and often quite more than that. Thus, due to the very social nature of storytelling, and the high frequency of it, we examined whether a 'narrative style' could be identified, and whether having such a style was associated with well-being.

We focused on a subset of participants and types of event (self-defining and transgression) to look at whether recognizability was associated with variability in narrative features. To assess recognizability we created a multiple-choice test about a subset of our participants in Study 1 for a new set of participants. We provided new participants with two narratives from one person. We then provided them a set of narratives that included several 'foils' along with the third narrative from the same person who wrote the initial two narratives. These new participants had to decipher which narrative 'matched' the first two, and we examined whether those who were more or less likely to be recognized, or 'matched' were more or less variable along the narrative dimensions investigated in Study 1 .

\section{Study 2: Method}

\section{Participants}

For Study 2, the primary participants were those who provided narratives, and who constitute a subset of the participants reported in Study 1. That is, from the sample in Study 1 we drew 116 individuals from those who reported self-defining memories or transgressions (79\% European-American; 75\% females; Age $M(S D)=19.5(2.2))$. We chose these two prompts because they represent the two different types of narratives - those closely linked to identity, and those which may be more likely to be distanced from the self - and which may be differentially recognizable. 
Secondary participants were drawn from the psychology participant pool at a large, Mountain West state institution. Onehundred and three participants $(n=48$ males; (Age $M(S D)=23.1(5.6) ; 74 \%$ European American) served as perceivers; 9 of the individuals provided only partial data.

\section{Procedure: Recognizability}

Procedures for the primary sample were described in Study 1. For the secondary sample, each of the new 'perceiver' participants provided consent, and then completed a multiple choice "test." Perceiver participants were presented with two narratives (all were transcribed and de-identified) from the same individual, and were then shown four additional narratives from participants in the sample, all in response to the same prompt. One of the four narratives was the third narrative from the target individual, while the other three narratives served as foils. The task for perceivers was to correctly identify, from the set of four, the narrative that 'matched' the initial two narratives. Each perceiver participant viewed narratives from 20 target participants - 10 for each prompt.

Prompts were blocked, and the order of prompts (self-defining, transgression) was counterbalanced across perceiver participants. Due to random assignment of rating packets, the 117 target participants were rated by a minimum of $6(n=1)$ and a maximum of $20(n=$

19) perceivers; the majority (83\%) of the sample were rated by at least 15 raters. Instructions were as follows:

We will be showing you narratives provided by participants like yourself — college students—from another university in another part of the United States. We will be asking you to view two stories by one individual, and then to determine from a set of additional narratives, which one was written by the same individual whose narratives you initially saw. We will ask you to do this for a total of 20 individuals' narratives.

\section{Measures}


All measures for narrative variability and well-being were described in Study 1.

Recognizability. To assess the extent to which participant's narratives were recognizable by a perceiver, we computed the percentage of correct identifications for each target participant, across all perceivers who evaluated him/her. Cronbach's alpha across 15 raters was .69 , suggesting adequate inter-rater consistency and supporting our aggregation. The resulting recognizability score ranged from 0 to $94, M(S D)=47.8(21.4)$. Note that some of the large range of variation in this measure could be due to some targets being rated by more accurate perceivers. Random assignment of perceivers to packets was done to equalize the average accuracy of the rater pool, but to further evaluate this, we examined the average accuracy of the rater pool for each target participant.

Descriptively, the average accuracy of the rater pool for each perceiver ranged from $32 \%$ to $62 \%(M(S D)=48.3(8.0)$, and the average accuracy of the rater pool for each target was only weakly correlated with the recognizability of target participants' narratives, $r(116)$ $=.16, p>.08$. Moreover, Cronbach's alpha computed across 15 raters was .67 , suggesting reasonable reliability among raters in identifying participants or not identifying them, which implies that the variability in recognizability scores is attributable to something about participants' narratives.

\section{Results: Study 2}

We based our sample size for the recognizability analyses on feasibility given the novel approach to person perception using narratives. To asses our power to detect effects we examined sample size needs for correlational analyses using G*power (Faul et al., 2007), given an alpha of .05 and desired power of .80 . These analyses suggested we had adequate power across the sample to detect 
medium correlations, but less than adequate power for within-event type analyses, where null results need to be interpreted with caution. Data for these latter analyses are consequently reported with $95 \%$ confidence intervals.

\section{Is narrative variability related to psychological adjustment or narrative recognizability?}

Across the whole sample, recognizability was moderate - the average proportion of perceivers that correctly identified a participants' third narrative was just below $50 \%, M(S D)=47.8(21.4)$. This is significantly larger than the $25 \%$ expected by chance, $t(118)=11.6, p<.001$. The resulting difference can be translated to a cohen's $d=1.06$, which is a large effect (Cohen, 1988). This proportion was slightly but not significantly lower for transgressions, $M(S D)=46.0(20.4)$ than for self-defining memories, $M(S D)=$ 49.7(22.4).

Our next question was whether recognizability was linked to variability. These results are presented in Table 4 , for the overall sample and separately for self-defining and transgression memories. Table 4 also includes correlations between recognizability and average narrative scores, and given our small sample size for correlational analyses, presents 95\% confidence intervals for all analyses. As seen there, in the overall sample, there were few significant correlations between recognizability and average narrative features or residualized variability in narrative features. When such correlations were more noteworthy, based on confidence intervals, they generally showed greater variability relating to lower recognizability.

Our final question concerned recognizability and well-being. Recognizability was largely uncorrelated with measures of wellbeing, whether for the total sample ( $r$ 's ranged from .01 to .11), the subsample who wrote about self-defining memories ( $r$ 's ranged 
from .01 to .12), or the subsample who wrote about transgression memories ( $\mid r$ 's ranged from .01 to .24); the only notable exception was a trending positive relationship between depression scores and higher recognizability within transgression narratives, $r=.24, p<$ .10. Thus, recognizability captures something largely distinct from traditional measures of well-being.

\section{Discussion}

Overall, our data suggest that the nature and implications of within-person variability in narrative depend a good deal on the feature of narrative, and on the type of event being narrated. Thus, we emphasize that the question of intra-individual variability in narrative is one that needs to be clearly specified: variability in what feature of narrative, and variability in what context. Further, although narratives appear to be recognizable, if recognizability is related to variability, it is not due to variability in the features we examined.

At the outset, it is important to note that variability does not seem to be a property of the individual. That is, it is not the case that some people are more variable than others; rather, some aspects of narratives are more variable than others. Further, we had hypothesized that variability would be a property of the type of event, with self-defining and turning point memories generally more variable than more negative memories, but this was not the case. Of course, we did not examine all types of events, or all characteristics of narratives. However, given our power, we can be fairly confident that the types of events we examined are not meaningfully different on the narrative dimensions we assessed. Thus, narrative feature seems to be the most critical issue to attend to in examining this kind of variability, although event type does matter for associations between variability and well-being 
In terms of specific narrative characteristics, we examined intra-individual variability on four narrative dimensions: emotional expression (positive and negative), coherence, autobiographical reasoning (impact statements and meaning), and resolution. As predicted, we found the least variability in coherence, particularly chronological coherence. Because narrative coherence relies on broader cognitive and linguistic skills involved in creating a structured story, once individuals develop these skills by late adolescence (Reese et al., 2011), it makes sense that this would become a stable component of one's narrative production. We also found that there was less variability in positive emotion than in the other narrative dimensions. In the U.S. context, there is a higher value placed on positive emotions, which may lessen social and cultural constraints on such expressions (e.g., Tsai, Knudsen, \& Fung, 2006). In fact, positive emotion can be appropriate, or meaningful, in narrating positive or negative events; one is likely to narrate positive events with positive emotion, and one can also see a silver lining in negative events. The expression of negative emotion may be more variable because that expression is additionally affected by social constraints and socialization processes that result in variations of negative emotional expression across different experiences (Fivush, Berlin, Sales \& Mennuti-Washburn, \& Cassidy, 2003; Fivush \& Wang, 2005; McAdams, 2013; McLean \& Syed, under review).

In contrast to the low variability features, we saw higher variability in resolution, as expected. We had hypothesized this relation because of the idea that not all events need resolution, which could also account for the finding of high variability in positive impact statements. This is consistent with Fleeson's arguments that different situations pull for different aspects of personality to manifest, as well as recent arguments that aspects of autobiographical reasoning are event-specific (Greenhoot \& McLean, in 
preparation; Mansfield, 2015). However, it is also possible that resolution differs by when the event occurred. Events that occurred in the more distant past may have already been processed and resolved (and, therefore, also have less negative emotion expressed) than events in the more recent past (see Waters et al., 2013, for related findings). This would suggest that variability in resolution and negative affect may be at least partly a function of when the narrated events occurred in an individual's life course.

In terms of relations between variability and well-being, both narrative feature and event type mattered. For more negative events, in particular low points, it appears that variability in resolution is not indicative of healthy functioning, suggesting that these types of events demand a resolution and that those who are unable to do so may be at risk. For more identity-relevant narratives, such as self-defining memories, greater variability in autobiographical reasoning was not associated with healthy functioning, suggesting that not explicitly and consistently linking these events to the self may be problematic. Thus, finding an ending to more difficult events, perhaps to put them in the past and not let them linger, and connecting more identity relevant events to the self in explicit ways appear to be places where low variability is associated with positive functioning. Interestingly, for turning point memories, greater variability in meaning-making was associated with higher life satisfaction. Although we conceptualized self-defining and turning point memories as similar, these data suggest that there may be more room to vary in how one narrates a turning point. Turning points are viewed as experienced in which individuals changed their self-views. Perhaps some of those changes demand greater reasoning processes ("I distrust people more than I used to."), and that some do not (“I have grown more mature with age.”). Finally, we interpret some of these well-being results with caution because mean level interactions may matter. That is, the association between 
greater variability in negative impact statements in turning point memories and poorer well-being may differ depending on whether that variability is around a low or a high mean.

For coherence markers, we mainly saw associations with well-being in the self-defining memories, and those associations depended on the type of coherence. Greater variability in contextual coherence - the details necessary to understand what happened was associated with lower well-being. Yet variability in thematic coherence - detail necessary to understand the points of the story was associated with higher well-being. In terms of the former, if a story does not have enough, or the appropriate, details to understand it, this indicates real issues with basic story construction, and functioning more broadly. In terms of the latter, it may be that some stories demand greater affective and evaluative explanation, and some do not. For example, some experiences may be more broadly understood by the culture at large - such as getting an A on a test or falling in love - and thus may require less explanation. In contrast, some more idiosyncratic events may demand more contextual coherence. Those who narrate their experiences with greater sensitivity to these differences may be functioning at a higher level.

In general, we found more markers of variability associated with well-being in the context of self-defining memories. We speculate that to see associations between variability and standard well-being, the more relevant events are identity-central. Indeed, Waters and Fivush (2014) found that there were stronger relations between coherence and well-being for personal narratives that were especially self-defining. However, it could also be that variability in other events are related to other markers. For example, variability in transgressions may be related to aspects of morality or to social adjustment indicators. 
The final question we addressed was whether the aspects of narrative that are meaningful to narrative researchers, in terms of their association with well-being, are also the features that characterize someone's narrative voice to the naïve observer, and whether recognizability was related to variability and to well-being. Here, our main finding of interest was that it is possible to recognize people via their narratives in ways that are significantly above chance agreement. In fact, the difference in correct identifications between a chance level (25\%) and our observed level (48\%) is a relatively large effect size (cohen's $d=1.07)$. Expressed in the metric of $\mathrm{r}(.47)$, it suggests that recognizability of narratives is on the larger side, relative to work on the thin-slicing of traits, where r's range from .2 to .4 (e.g. Borkenau et al., 2004; Tackett et al., 2015). However, we still do not know what makes a person recognizable, as variability in the features we examined was not associated with recognizability. It may be that interactions between average levels of a given feature and variability may be important to recognizability, or that people are tapping into a dimension of the narratives that we did not assess. Finally, recognizability was not clearly associated with well-being, with one exception. Those who were more recognizable across transgressions tended to be more depressed. Given our sample size, and lack of hypotheses about this issue, we interpret this with caution, but this could reflect some sort of negative self-schema that is visible to others and reflects poor psychological functioning.

\section{Limitations and Conclusions}

Our first limitation is that we only examined variability within the same kinds of events, and there are other kinds of withinperson variation in narrative, such as variability in the narration of the same event over time or to different audiences, or variability in 
telling different types of events within persons ala Dunlop et al. (2013). There may also be developmental issues at play, which we could not examine. Dunlop's work, in which variability across different types of events was related to poorer adjustment, suggests that some kinds of variability may reflect lack of coherence in identity, perhaps especially in adults (see Noftle \& Fleeson, 2015, on developmental issues in variability). Indeed, we only examined one age group, and it is possible that the impact of variability in narrative may differ by developmental stages. Finally, from an analytical perspective, we focused tightly on within-person variability when controlling for between-person differences in the average level of those features; and as we mentioned above, recognizability and relations with well-being may depend on both average levels of narrative features and the variability of those features.

In sum, our current data, along with Dunlop's et al. (2013; see also Dunlop, 2015), suggest that examining intra-individual variability in narrative is a meaningful question for researchers to pursue. This initial examination showed us that narrative features and types of events are important to consider in thinking about variability in narratives, but much work still remains in this nascent topic. We hope these data inspire more empirical pursuits. 


\section{References}

Adler, J.M., Lodi-Smith, J., Phlippe, F.L., \& Houle, I. (2015). The incremental validity of narrative identity in predicting well-being: A review of the field and recommendations for the future. Personality and Social Psychology Review.

Alea, N., \& Bluck, S. (2003). Why are you telling me that? A conceptual model of the social function of autobiographical memory. Memory, 11, 165-178.

Baird, B. M., Le, K., \& Lucas, R. E. (2006). On the nature of intraindividual personality variability: Reliability, validity, and associations with well-being. Journal of Personality and Social Psychology, 90, 512-527.

Baker-Ward, L., Bauer, P. J., Fivush, R., Haden, C. A., Ornstein, P. A., \& Reese, E. (2007). Coding coherence in autobiographical narratives. Symposium at the biennial meetings of the Society for Research in Memory and Cognition, Lewiston, ME.

Banks, M. V., \& Salmon, K. (2013). Reasoning about the self in positive and negative ways: Relationship to psychological functioning in young adulthood. Memory, 21(1), 10-26.

Baumeister, R. F., Stillwell, A., \& Wotman, S. R. (1990). Victim and perpetrator accounts of interpersonal conflict: Autobiographical narratives about anger. Journal of Personality and Social Psychology, 59, 994-1005.

Blagov, P. S., \& Singer, J. A. (2004). Four dimensions of self-defining memories (specificity, meaning, content, and affect) and their relationships to self-restraint, distress, and repressive defensiveness. Journal of Personality, 72, 481-511.

Block, J. (1981). Some enduring and consequential structures of personality. In A. I. Rabin (Ed.), Further explorations in personality 
(pp. 27 -43). New York: John Wiley.

Borkenau, P., Mauer, N., Riemann, R., Spinath, F. M. \& Angleitner, A. (2004). Thin slices of behavior as cues of personality and intelligence. Journal of Personality and Social Psychology, 86, 599-614.

Bruner, J. S. (1990). Acts of meaning. Cambridge, MA: Harvard University Press.

Cohen, J. (1988). Statistical power analysis for the behavioral sciences. Hillsdale, NJ: Lawrence Erlbaum.

Costa, P. T. Jr., \& McCrae, R. R. (1994). Set like plaster? Evidence for the stability of adult personality. In T. F. Heatherton \& J. L. Weinberger (Eds.), Can personality change? (pp. 21-40). Washington, DC: APA Books.

Côté, S., Moskowitz, D. S., \& Zuroff, D. C. (2012). Social relationships and intraindividual variability in interpersonal behavior: Correlates of interpersonal spin. Journal of Personality and Social Psychology, 102, 646-659.

Diener, E., Emmons, R. A., Larsen, R. J., \& Griffin, S. (1985). The Satisfaction with life scale. Journal of Personality Assessment, 49, $71-75$.

Donahue, E.M., Robins, R.W., Roberts, B.W., John, O.P. (1993). The divided self: Concurrent and longitudinal effects of psychological adjustment and social roles on self-concept differentiation. Journal of Personality and Social Psychology, 64, 834-846.

Dunlop, W. L. (2015). Contextualized personality, beyond traits. European Journal of Personality.

Dunlop, W. L., Walker, L. J., \& Wiens, T. K. (2013). What do we know when we know a person across contexts? The differing 
relationship between self-concept differentiation and adjustment at the three levels of personality. Journal of Personality, 81, 376-389.

Empirisoft. (2008) Media Lab v2008 [computer software]. http://www.empirisoft.com.

Faul, F., Erdfelder, E., Lang, A.-G., \& Buchner, A. (2007). G*Power 3: A flexible statistical power analysis program for the social, behavioral, and biomedical sciences. Behavior Research Methods, 39, 175-191.

Fivush, R., Berlin, L. J., Sales, J. M., Mennuti-Washburn, J., \& Cassidy, J. (2003). Functions of parent-child reminiscing about emotionally negative events. Memory, 11(2), 179-192.

Fivush, R., Bohanek, J.G., \& Duke, M. (2008). The intergenerational self: Subjective perspective and family history. In F. Sani (Ed.). Individual and Collective Self-Continuity. Mahwah, NJ: Erlbaum.

Fivush, R., Merrill, N., \& Waters, T.E.A. (in press). Connecting the self to traumatic and positive events: Links to identity and growth. Memory.

Fivush, R., Sales, J. M., \& Bohanek, J. G. (2008). Meaning making in mothers' and children's narratives of emotional events. Memory, 16(6), 579-594.

Fivush, R., \& Wang, Q. (2005). Emotion Talk of Mother-Child Conversations of the Shared Past: The Effects of Culture, Gender, Event Valence. Journal of Cognition and Development, 6(4), 489-506.

Fivush, R. \& Zaman, W. (2015). Gendered Narrative Voices: Sociocultural and Feminist Approaches to Emerging Identity in 
Childhood and Adolescence. In K. C. McLean \& M. Syed (Eds.), The Oxford Handbook of Identity Development. New York: Oxford.

Fleeson, W. (2001). Toward a structure- and process-integrated view of personality: Traits as density distributions of states. Journal of Personality and Social Psychology, 80(6), 1011-1027.

Fleeson, W., \& Jayawickreme, E. (2015). Whole Trait Theory. Journal of Research in Personality, 56, 82-92.

Fournier, M. A., Moskowitz, D. S., \& Zuroff, D. C. (2009). The interpersonal signature. Journal of Research in Personality, 43(2), $155-162$.

Funder, D. C. (1983). Three Issues in Predicting More of the People: A Reply to Mischel and Peake. Psychological Review, 90, $283-290$.

Greenhoot, A. F., \& McLean, K. C. (in preparation). The costs and benefits of reflection in personal narratives: The type of memory matters.

Greenhoot, A. F., Sun, S., Bunnell, S. L., \& Lindboe, K. (2013). Making sense of traumatic memories: Memory qualities and psychological symptoms in emerging adults with and without abuse histories. Memory, 21, 125-142.

Habermas, T., \& Bluck, S. (2000). Getting a life: The development of the life story in adolescence. Psychological Bulletin, 126, 748-769.

Habermas, T., \& de Silveira, C. (2008). The development of global coherence in life narratives across adolescence: Temporal, causal, and thematic aspects. Developmental Psychology, 44, 707-721.

Human, Lauren J.; Biesanz, Jeremy C.; Finseth, Sonia M.; Pierce, Benjamin; Le, Marina (2014). To thine own self be true: 
Psychological adjustment promotes judgeability via personality-behavior congruence. Journal of Personality and Social Psychology, 106(2), 286-303.

Josselson, R. (2009). The present of the past: Dialogues with memory over time. Journal of Personality, 77, $647-668$.

King, L. A., Scollon, C. K., Ramsey, C. M., \& Williams, T. (2000). Stories of life transition: Happy endings, subjective well-being, and ego development in parents of children with Down Syndrome. Journal of Research in Personality, 34, 509-536.

Lilgendahl, J. L. (2014). The Dynamic Role of Identity Processes in Personality Development: Theories, Patterns, and New Directions. In K. C. McLean \& M. Syed (Eds.), The Oxford Handbook of Identity Development. New York: Oxford.

Lilgendahl, J.P., \& McAdams, D.P. (2011). Constructing stories of self-growth: How individual differences in patterns of autobiographical reasoning relate to well-being in midlife. Journal of Personality, 79, 391-428.

Lilgendahl, J. P., McLean, K. C., \& Mansfield, C. D. (2013). When is meaning making unhealthy for the self? The roles of neuroticism, implicit theories, and memory telling in trauma and transgression memories. Memory, 21(1), 79-96.

Mansfield, C. D. (2015). Do Different Types of Negative Events Lead to Distinct Adaptive Functioning Threats? Doctoral dissertation, University of Utah.

Mansfield, C. D., McLean, K. C., \& Lilgendahl, J. P. (2010). Narrating traumas and transgressions: Links between narrative processing, wisdom, and well-being. Narrative Inquiry, 20(2), 246-273.

Mansfield, C. D., Pasupathi, M., \& McLean, K. C. (2015). Is narrating growth in stories of personal transgressions associated with 
increased well-being, self-compassion, and forgiveness of others? Journal of Research in Personality, 58, 69-83.

McAdams, D. P. (1988). Power, intimacy, and the life story: Personological inquiries into identity. New York: Guilford.

McAdams, D. P. (1995). What do we know when we know a person? Journal of Personality, 63, 365-396.

McAdams, D. P. (2006). Foley Center, Guided Autobopgraphy. Retrieved November 20, 2006,

from http://www.sesp.northwestern.edu/foley/instruments/guided.

McAdams, D. P. (2013). The redemptive self: Stories Americans live by. New York: Oxford University Press.

McAdams, D. P., Anyidoho, N. A., Brown, C., Huang, Y. T., Kaplan, B., Machado, M. A. (2004). Traits and stories: Links between dispositional and narrative features of personality. Journal of Personality, 72(4), 761-784.

McAdams, D. P., Bauer, J. J., Sakaeda, A. R., Anyidoho, N. A., Machado, M. A., Magrino-Failla, K., White, K., \& Pals, J. L. (2006). Continuity and change in the life story: A longitudinal study of autobiographical memories in emerging adulthood. Journal of personality, 74(5), 1371-1400.

McAdams, D. P., \& Cox, K. S. (2010). Self and identity across the life span in A. Freund and R. Lerner (Eds.), Handbook of lifespan development: Vol. 2 (pp. 158-207). New York: Wiley.

McAdams, D. P., \& Manczak, E. (2011). What is a "level" of personality?. Psychological Inquiry, 22: 40-44.

McAdams, D. P., \& McLean, K. C. (2013). Narrative Identity. Current Directions in Psychological Science, 22, $233-238$.

McAdams, D. P., \& Olson, B. D. (2010). Personality development: Continuity and change. in S. Fiske, D. Schacter, and R. Sternberg 
(Eds.), Annual review of psychology, Vol. 61 (pp. 517-542). Palo Alto, CA: Annual Reviews, Inc.

McLean, K. C. (2005). Late adolescent identity development: Narrative meaning-making and memory telling. Developmental Psychology, 41, 683-691.

McLean, K. C. (2008). Stories of the young and the old: Reflections on self-continuity. Developmental Psychology, 44, $254-164$.

McLean, K. C. (2015). The Co-authored Self: Family Stories and the Construction of Personal Identity. New York: Oxford .

McLean, K. C. \& Jennings, L. E. (2012). Teens Telling Tales: How Maternal and Peer Audiences Support Narrative Identity Development. Journal of Adolescence, 35, 1455-1469.

McLean, K. C., \& Pasupathi, M. (2011). Old, New, Borrowed, and Blue? The emergence and retention of meaning in autobiographical storytelling. Journal of Personality, 79, 135 - 164.

McLean, K. C., Pasupathi, M., \& Pals, J. L. (2007). Selves creating stories creating selves. Personality and Social Psychology Review, $11,262-278$.

McLean, K. C., \& Pratt, M. W. (2006). Life's little (and big) lessons: Identity statuses and meaning-making in the turning point narratives of emerging adults, Developmental Psychology, 42, 714-722.

McLean, K. C. \& Syed, M. (under review). Personal, Master, and Alternative Narratives: An Integrative Framework for Understanding Identity Development in Context.

McLean, K. C., \& Thorne, A. (2003). Late adolescents' self defining memories about relationships. Developmental Psychology, 30, 
635-645.

McLean, K. C., Wood, R., \& Breen, A. (2013). Reflecting on a difficult life: Narrative construction and delinquency in vulnerable adolescents and the hazards of reflecting on difficult experiences. Journal of Adolescent Research, 28, 431-452.

Mischel, W., \& Peake, P. K. (1982). Analyzing the construction of consistency in personality. Nebraska symposium on motivation (pp. 233-262). Lincoln: University of Nebraska Press.

Mischel, W., \& Peake, P. K. (1983). Analyzing the construction of consistency in personality. In M. M. Page (Ed.), PersonalityCurrent theory and research (pp. 233-262). Lincoln: University of Nebraska Press.

Mischel, W., \& Shoda, Y. (1995). A cognitive-affective system theory of personality: Reconceptualizing situations, dispositions, dynamics, and invariance in personality structure. Psychological Review, 102(2), 246-268.

Noftle, E. E., \& Fleeson, W. (2010). Age differences in big five behavior averages and variabilities across the adult lifespan: Moving beyond retrospective, global summary accounts of personality. Psychology and Aging, 25, 95-107.

Noftle, E. E., \& Fleeson, W. (2015). Intraindividual variability in adult personality development. In M. Diehl, K. Hooker, \& M. J. Sliwinski (Eds.), Handbook of intraindividual variability across the lifespan (pp. 176-197). Routledge: New York.

Pals, J. L. (2006). Narrative identity processing of difficult life experiences: Path-ways of personality development and positive selftransformation in adult-hood. Journal of Personality, 74, 1079-1110.

Pasupathi, M. (2001). The social construction of the personal past and its implications for adult development. Psychological Bulletin, 


\section{7, 651-672.}

Pasupathi, M., Billitteri, J., Mansfield, C. D., Wainryb, C., Hanley, G. E., \& Taheri, K. (2015). Regulating emotion and identity by narrating harm. Journal of Research in Personality, 58, 127-136.

Pasupathi, M., Mansour, E., \& Brubaker, J. R. (2007). Developing a life story: Constructing relations between self and experience in autobiographical narratives. Human Development, 50, 85-110.

Pasupathi, M. McLean, K. C., Fivush, R., Greenhoot, A. F., Wainryb, C. (in preparation). Narrative Identity: Stability and Flexibility Within Persons.

Pasupathi, M., McLean, K. C., \& Weeks, T. (2009). The told and untold narrative self. Journal of Personality, 77, 89-124.

Pasupathi, M., \& Oldroyd, K. (in press). What varies, how, and across what contexts? European Journal of Personality.

Pasupathi, M., \& Wainryb, C. (2010). Developing moral agency through narrative. Human Development, 53, 55-80.

Pennebaker, J.W., Booth, R.J., \& Francis, M.E. (2007). Linguistic Inquiry and Word Count: LIWC2007. LIWC.net, Austin, TX.

Pennebaker, J. W., \& Chung, C. K. (2011). Expressive writing and its links to mental and physical health. In H. S.

Friedman (Ed.), Oxford handbook of health psychology. New York, NY: Oxford University Press.

Radloff, L. S. (1977). The CES-D scale a self-report depression scale for research in the general population. Applied psychological measurement, 1(3), 385-401. 
Reese, E. Haden, C. A., Baker-Ward, L., Bauer, P., Fivush, R., \& Ornstein, P. A. (2011). Coherence of personal narratives across the lifespan: A multidimensional model and coding method. Journal of Cognition and Development, 12(4),424-462.

Rimé, B., Mesquita, B., Philippot, P., \& Boca, S. (1991). Beyond the emotional event: Six studies on the social sharing of emotion. Cognition \& Emotion, 5, 435-465.

Roberts, B. W., \& DelVecchio, W. (2000). The rank-order consistency of personality from childhood to old age: A quantitative review of longitudinal studies. Psychological Bulletin, 126, 3-25.

Singer, J. A. (2004). Narrative identity and meaning making across the adult span: An Introduction. Journal of Personality, 72, 437-459.

Singer, J. A., \& Moffitt, K. H. (1991-1992). An experimental investigation of specificity and generality in memory narratives. Imagination, Cognition, and Personality, 11, 233-257.

Tackett, J. L., Herzhoff, K., Kushner, S. C., \& Rule, N. (2015). Thin slices of child personality: Perceptual, situational, and behavioral contributions. Journal of Personality and Social Psychology.

Thorne, A. (2000). Personal memory telling and personality development. Personality and Social Psychology Review, 4, 45-56.

Thorne, A., Cutting, L., \& Skaw, D. (1998). Young adults' relationship memories and the life story: Examples or essential landmarks? Narrative Inquiry, 8, 1-32.

Thorne, A., McLean, K. C., \& Lawrence, A. M. (2004). When remembering is not enough: Reflecting on self-defining memories in late adolescence. Journal of Personality, 72, 513-541. 
Tsai, J.L., Knutson, B., \& Fung, H.H. (2006). Cultural variation in affect valuation. Journal of Personality and Social Psychology, 90, 288-307.

Waters, E. A. Bauer, P. J., \& Fivush, R. (2013). Autobiographical memory functions served by multiple event types. Applied Cognitive Psychology, 2, 185-195.

Waters, T. E., \& Fivush, R. (2014). Relations Between Narrative Coherence, Identity, and Psychological Well-Being in Emerging Adulthood. Journal of Personality.

Waters, T. E., Shallcross, J. F., \& Fivush, R. (2013). The many facets of meaning making: Comparing multiple measures of meaning making and their relations to psychological distress. Memory, 21(1), 111-124.

Weeks, T. L., \& Pasupathi, M. (2010). Autonomy, identity, and narrative construction with parents and friends. In McLean, K. C., \& Pasupathi, M., (Eds.) Narrative identity development in adolescence: Creating the storied self (pp. 65-92). New York: Springer. 
Table 1: Descriptive statistics for variables included in the analyses

\begin{tabular}{|c|c|c|c|c|c|c|c|c|c|}
\hline & $\mathrm{N}$ & Min & Max & Mean (SD) & $\begin{array}{c}95 \% \mathrm{CI} \\
\text { of the Mean }\end{array}$ & $\begin{array}{c}\text { Variability } \\
M(S D)\end{array}$ & $\begin{array}{c}95 \% \text { CI } \\
\text { Of } \\
\text { Variability } \\
\text { Mean } \\
\end{array}$ & $\begin{array}{c}\text { Proportional } \\
\text { Variability } \\
\text { M(SD) }\end{array}$ & $\begin{array}{c}95 \% \text { CI of } \\
\text { Proportional } \\
\text { Variability } \\
\text { Mean }\end{array}$ \\
\hline Life Satisfaction & 527 & 1 & 7 & $5.0(1.2)$ & $4.8-5.1$ & -- & & -- & \\
\hline $\begin{array}{l}\text { Depression } \\
\text { Narrative Features }\end{array}$ & 527 & 0 & 53 & $15.3(10.0)$ & $14.5-16.2$ & -- & & -- & \\
\hline Positive Emotion & 547 & 0 & 10 & $1.37(.91)$ & $1.29-1.44$ & $1.01(.79)$ & $.95-1.09$ & $.10(.10)$ & $.10-.11$ \\
\hline Negative Emotion & 547 & 0 & 7 & $2.35(1.32)$ & $2.24-2.46$ & $1.28(.97)$ & $1.20-1.37$ & $.18(.14)$ & $.17-.20$ \\
\hline Chronological Coherence & 547 & 1 & 3 & $2.79(.40)$ & $2.75-2.82$ & $.21(.34)$ & $.18-.24$ & $.10(.17)$ & $.09-.12$ \\
\hline Contextual Coherence & 547 & 1 & 3 & $2.49(.44)$ & $2.46-2.53$ & $.39(.33)$ & $.36-.42$ & $.20(.16)$ & $.18-.21$ \\
\hline Thematic Coherence & 547 & 1 & 3 & $2.21(.58)$ & $2.16-2.25$ & $.40(.35)$ & $.37-.43$ & $.20(.17)$ & $.19-.22$ \\
\hline Meaning & 546 & 0 & 3 & $.69(.86)$ & $.62-.76$ & $.62(.70)$ & $.56-.68$ & $.21(.23)$ & $.19-.23$ \\
\hline Positive/Neutral Impacts & 547 & 0 & 1 & $.16(.31)$ & $.14-.19$ & $.18(.30)$ & $.15-.20$ & $.18(.30)$ & $.15-.20$ \\
\hline Negative Impacts & 547 & 0 & 1 & $.19(.30)$ & $.16-.21$ & $.23(.34)$ & $.20-.26$ & $.23(.34)$ & $.21-.26$ \\
\hline Resolution & 543 & 0 & 2 & $.89(.70)$ & $.83-.95$ & $.61(.53)$ & $.57-.66$ & $.31(.27)$ & $.28-.33$ \\
\hline
\end{tabular}

Note. Variable n's are due to missing data. 
Table 2: Correlations among Variability Scores for Narrative Features

\begin{tabular}{|c|c|c|c|c|c|c|c|c|c|}
\hline & $\begin{array}{l}\text { Positive } \\
\text { Emotion }\end{array}$ & $\begin{array}{l}\text { Negative } \\
\text { Emotion }\end{array}$ & $\begin{array}{c}\text { Chronological } \\
\text { Coherence }\end{array}$ & $\begin{array}{l}\text { Contextual } \\
\text { Coherence }\end{array}$ & $\begin{array}{l}\text { Thematic } \\
\text { Coherence }\end{array}$ & Meaning & $\begin{array}{l}\text { Pos/Neutral } \\
\text { Impacts }\end{array}$ & $\begin{array}{l}\text { Negative } \\
\text { Impacts }\end{array}$ & Resolution \\
\hline Positive Emotion & 1 & $.13 * *$ & $.25 * * *$ & .06 & -.05 & .00 & .04 & $-.09 *$ & .00 \\
\hline Negative Emotion & $.13 * *$ & 1 & $.10^{*}$ & .03 & -.04 & $-.11 *$ & $-.11 *$ & -.02 & -.03 \\
\hline Chronological Coherence & $.12 * *$ & -.00 & 1 & $.23 * * *$ & -.02 & -.02 & .02 & .00 & -.05 \\
\hline Contextual Coherence & .04 & -.00 & .08 & 1 & .02 & -.03 & -.00 & -.03 & -.04 \\
\hline Thematic Coherence & -.01 & .01 & -.01 & -.00 & 1 & $.15 * *$ & .03 & .06 & .08 \\
\hline Meaning & -.01 & .03 & -.01 & -.03 & .03 & 1 & $.36 * * *$ & $.13 * *$ & .07 \\
\hline Positive/Neutral Impacts & -.03 & -.05 & .04 & -.00 & -.00 & .01 & 1 & $.10 *$ & $.17 * * *$ \\
\hline Negative Impacts & .03 & .09 & -.07 & .00 & .07 & .06 & .08 & 1 & .03 \\
\hline Resolution & -.02 & -.11 & -.04 & -.02 & -.02 & -.02 & .09 & .02 & 1 \\
\hline
\end{tabular}

Values above the diagonal reflect correlations with raw variability scores; below the diagonal are correlations with residualized variability scores controlling for mean levels on that feature.

${ }^{*} \mathrm{p}<.05,{ }^{* *} \mathrm{p}<.01, * * * \mathrm{p}<.001$ 
Table 3: Correlations between residualized variability scores for all narrative features and well-being.

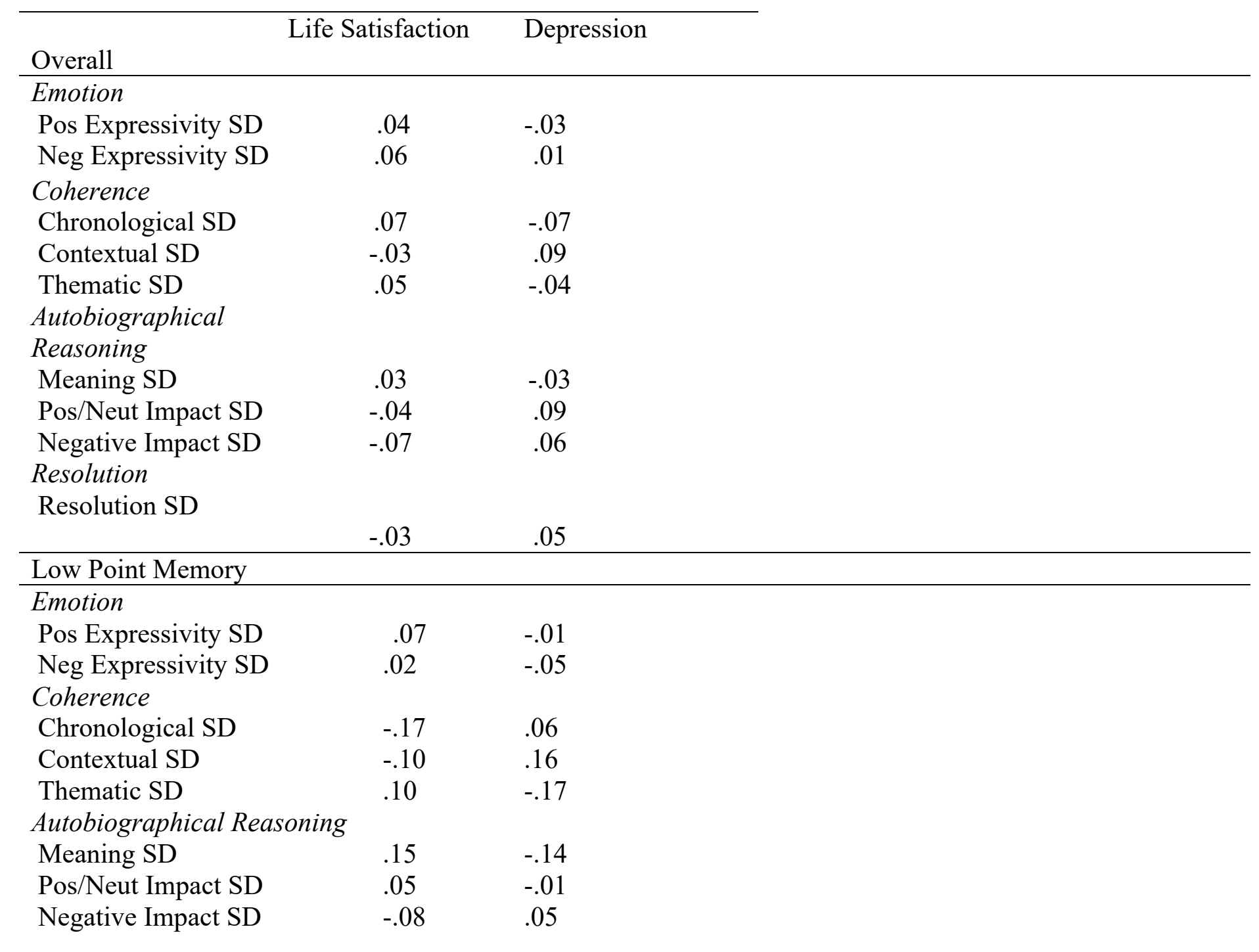


Resolution

Resolution SD

$-.10$

$.31 * *$

Self-Defining

Memory

Emotion

Pos Expressivity SD

Neg Expressivity SD

$.07 \quad-.10$

Coherence

Chronological SD

Contextual SD

$.20 *-.04$

Thematic SD

$.07 \quad-.01$

$-.25 * * \quad .15$

Autobiographical Reasoning

Meaning SD

$.20 * \quad-.03$

Pos/Neut Impact SD

Negative Impact SD

$-.21 * \quad .18$

$-.23^{*} \quad .25^{* *}$

$.06 \quad-.06$

Resolution

Resolution SD

$.05 \quad .01$

Transgression

Memory

\section{Emotion}

Pos Expressivity SD

Neg Expressivity SD

$.13-.03$

Coherence

Chronological SD

Contextual SD

$.09-.08$
-13

$.13-.12$

Thematic SD

$\begin{array}{ll}. .06 & .20 *\end{array}$

Autobiographical Reasoning

Meaning SD

$.06 \quad .01$

Pos/Neut Impact SD
Negative Impact SD

$\begin{array}{ll}-.00 & -.07\end{array}$

$.09 \quad .09$

Resolution 


\begin{tabular}{|c|c|c|}
\hline Resolution SD & .07 & -.14 \\
\hline \multicolumn{3}{|l|}{ Traumatic Memory } \\
\hline \multicolumn{3}{|l|}{ Emotion } \\
\hline Pos Expressivity SD & -.08 & .00 \\
\hline Neg Expressivity SD & -.04 & .05 \\
\hline \multicolumn{3}{|l|}{ Coherence } \\
\hline Chronological SD & -.03 & -.16 \\
\hline Contextual SD & .05 & -.04 \\
\hline Thematic SD & -.07 & .07 \\
\hline \multicolumn{3}{|c|}{ Autobiographical Reasoning } \\
\hline Meaning SD & .00 & -.07 \\
\hline Pos/Neut Impact SD & -.02 & -.01 \\
\hline Negative Impact SD & -.09 & .16 \\
\hline \multicolumn{3}{|l|}{ Resolution } \\
\hline Resolution SD & -.02 & .03 \\
\hline \multicolumn{3}{|l|}{$\begin{array}{l}\text { Turning Point } \\
\text { Memory }\end{array}$} \\
\hline \multicolumn{3}{|l|}{ Emotion } \\
\hline Pos Expressivity SD & .01 & .01 \\
\hline Neg Expressivity SD & .03 & .08 \\
\hline \multicolumn{3}{|l|}{ Coherence } \\
\hline Chronological SD & $.23 *$ & -.12 \\
\hline Contextual SD & .16 & .04 \\
\hline Thematic SD & .01 & -.04 \\
\hline \multicolumn{3}{|c|}{ Autobiographical Reasoning } \\
\hline Meaning SD & $.20 *$ & -.12 \\
\hline Pos/Neut Impact SD & -.03 & .09 \\
\hline Negative Impact SD & $-.23 *$ & .12 \\
\hline \multicolumn{3}{|l|}{ Resolution } \\
\hline Resolution SD & -.12 & .05 \\
\hline
\end{tabular}

Note. All correlations presented control for average levels and the square of average levels of that variable. 
$* \mathrm{p}<.05, * * \mathrm{p}<.01$.

Table 4: Correlations of Recognizability with Narrative Features for Study 2

\begin{tabular}{|c|c|c|}
\hline Overall & $\begin{array}{l}\text { Recognizability } \\
\text { with Average } \\
\text { Narrative Features } \\
(95 \% \mathrm{CI})\end{array}$ & $\begin{array}{l}\text { Recognizability } \\
\text { with Residualized } \\
\text { Variability Scores } \\
(95 \% \text { CI })\end{array}$ \\
\hline \multicolumn{3}{|l|}{ Emotion } \\
\hline Pos Expressivity & $.19 *(.05$ to .32$)$ & $.04(-.16$ to .24$)$ \\
\hline Neg Expressivity & $.17(-.04$ to .35$)$ & $-.12(-.29$ to .08$)$ \\
\hline \multicolumn{3}{|l|}{ Coherence } \\
\hline Chronological & $-.08(-.26$ to .10$)$ & $-.01(-.25$ to .19$)$ \\
\hline Contextual & $-.05(-.24$ to .14$)$ & $-.14(-.33$ to .06$)$ \\
\hline Thematic & $.03(-.16$ to .22$)$ & $-.00(-.18$ to .18$)$ \\
\hline \multicolumn{3}{|l|}{$\begin{array}{l}\text { Autobiographical } \\
\text { Reasoning }\end{array}$} \\
\hline Meaning & $.09(-.09$ to .26$)$ & $.07(-.10$ to .25$)$ \\
\hline Pos/Neut Impact & $.04(-.16$ to .26$)$ & $.01(-.17$ to .20$)$ \\
\hline Negative Impact & $-.09(-.28$ to .11$)$ & $-.11(-.27$ to .08$)$ \\
\hline \multicolumn{3}{|l|}{ Resolution } \\
\hline Resolution & $.09(-.11$ to .28$)$ & $.14(-.02$ to .31$)$ \\
\hline \multicolumn{3}{|c|}{ Self-Defining } \\
\hline \multicolumn{3}{|l|}{ Emotion } \\
\hline Pos Expressivity & $.23(-.00$ to .41$)$ & $-.06(-.31$ to .19$)$ \\
\hline Neg Expressivity & $.13(-.13$ to .35$)$ & $-.07(-.33$ to .20$)$ \\
\hline \multicolumn{3}{|l|}{ Coherence } \\
\hline Chronological & $-.15(-.30$ to .04$)$ & .04 (-.19 to .27$)$ \\
\hline Contextual & $-.06(-.30$ to .20$)$ & $-.22(-.45$ to .02$)$ \\
\hline Thematic & $-.04(-.31$ to .25$)$ & $.14(-.13$ to .40$)$ \\
\hline \multicolumn{3}{|l|}{$\begin{array}{l}\text { Autobiographical } \\
\text { Reasoning }\end{array}$} \\
\hline Meaning & $-.00(-.23$ to .23$)$ & .15 (-.13 to .42$)$ \\
\hline
\end{tabular}




\begin{tabular}{lll} 
Pos/Neut Impact & $-.07(-.37$ to .22$)$ & $-.03(-.29$ to .21$)$ \\
$\begin{array}{l}\text { Negative Impact } \\
\text { Resolution }\end{array}$ & $-.17(-.42$ to .08$)$ & $-.24(-.44$ to -.04$)$ \\
Resolution & $.02(-.31$ to .30$)$ & $13(-.15$ to .39$)$ \\
\hline & Transgression & \\
\hline $\begin{array}{l}\text { Emotion } \\
\text { Pos Expressivity }\end{array}$ & $.09(-.10$ to .32$)$ & $.03(-.24$ to .31$)$ \\
Neg Expressivity & $.29 *(.03$ to .52$)$ & $-.22(-.46$ to .03$)$ \\
$\begin{array}{l}\text { Coherence } \\
\text { Chronological }\end{array}$ & $-.03(-.34$ to .25$)$ & $-.07(-.42$ to .24$)$ \\
Contextual & $-.10(-.36$ to .16$)$ & $-.04(-.33$ to .25$)$ \\
Thematic & $.07(-.21$ to .33$)$ & $-.11(-.37$ to .12$)$ \\
$\begin{array}{l}\text { Autobiographical } \\
\text { Reasoning }\end{array}$ & & \\
Meaning & $.17(-.13$ to .43$)$ & $.00(-.26$ to .27$)$ \\
Pos/Neut Impact & $.14(-.13$ to .49$)$ & $-.03(-.23$ to .46$)$ \\
Negative Impact & $-.01(-.27$ to .27$)$ & $.06(-.22$ to .34$)$ \\
Resolution & & \\
Resolution & $.10(-.17$ to .36$)$ & $.15(-.03$ to .34$)$ \\
\hline
\end{tabular}

Residualized scores reflect variability controlled for average and squared average. ${ }^{*} \mathrm{p}<.05$ 